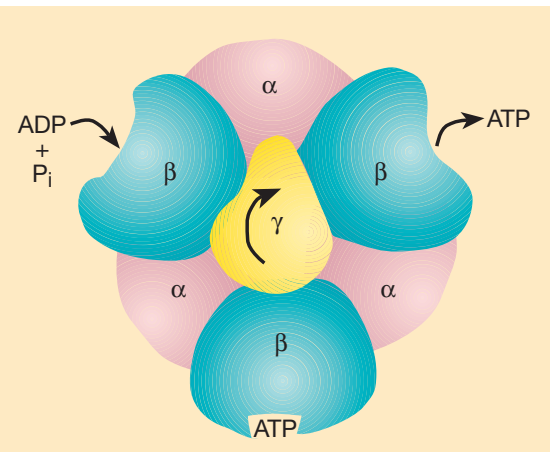

Figure 2 How rotation of the $\gamma$ subunit drives catalysis. During ATP synthesis, rotation of the $\gamma$ subunit causes sequential changes in the $\beta$ subunits. A rotation of $120^{\circ}$ changes the $\beta$ subunit that binds ADP and $P_{i}$ to a form with tightly bound ATP. The subunit with tightly bound ATP then changes to a form that releases ATP, and the third subunit prepares to bind another ADP and $P_{i}$.

ability of the X-ray structure also allowed clever disulphide cross-linking experiments to be designed, showing the positional interchange of the $\beta$ subunits as catalysis proceeds $s^{6,7}$. Specialized fluorescence techniques provided strong evidence for the rotation ${ }^{8}$. Rotational catalysis finally became widely accepted in 1997 when Noji et al. ${ }^{9}$ dramatically showed the rotation directly. They attached a fluorescently labelled actin filament to the $\gamma$ subunit of the $F_{1}$ portion fixed on a slide, then watched the filament spin as the enzyme cleaved ATP.

Other studies have looked into the arrangement of the subunits (Fig. 1). The many copies of the $c$ subunit in the $\mathrm{F}_{0}$ portion are arranged in a ring, with a conserved carboxyl group near the middle of one of the two hydrophobic helices that cross the membrane. These two helices are connected by a polar loop with conserved residues. The $b$ and $\delta$ subunits form a stator, which assures that rotational movement of the $\gamma$ subunit drives conformational changes in the $\beta$ subunits. The $\epsilon$ and $\gamma$ subunits contact each other and the polar loop of subunit $c$. The $a$ subunit contacts the ring of $c$ subunits and provides groups that probably participate in proton transfer through the $\mathrm{F}_{0}$ portion. Such proton transfer is thought to cause the ring of $c$ subunits to move in a step-wise fashion relative to the $a$ subunit. This results, in turn, in rotation of the $\epsilon$ and $\gamma$ subunits.

But does proton translocation cause meaningful changes in the conformation of the $c$ subunit - changes that might drive the rotation? This is the problem that has been elegantly addressed by Rastogi and Girvin ${ }^{1}$. To do this, they used two main methods. One was to measure the location and distance constraints provided by selected cysteine insertions that allowed disulphide-bond formation. The other was NMR, which gave structure and distance constraints from ${ }^{13} \mathrm{C}$ - and ${ }^{15} \mathrm{~N}$-resolved three-dimensional NOESY data.

Fillingame and colleagues ${ }^{10}$ have used the NMR approach to provide a structure for the monomeric $c$ subunit. Combining this with disulphide-crosslinking and other data, these authors developed a model for the structure of the $c$-subunit ring and its interactions with the $a$ subunit. They found that the key residue, an aspartic acid at position 61 (Asp 61), was lodged at the centre of four $\alpha$-helices of a $c-c$ dimer. They proposed that, as deprotonation and protonation occur when the ring of $c$ subunits interacts with the a subunit, the critical carboxyl group might move towards the periphery of the ring by a swivelling of adjacent helices.

The oligomeric model developed by Rastogi and Girvin ${ }^{1}$ provides insight into the catalytic mechanism. These authors deduced the conformations of the protonated and deprotonated forms of the $c$ subunit. When Asp 61 is deprotonated, there is a dramatic $140^{\circ}$-rotation of the carboxy-terminal helix with respect to the amino-terminal helix. The authors suggest two ways in which rotation of this helix might drive rotation of the $\gamma$ subunit. In one, the $a$ subunit moves with the carboxy-terminal helix of the $c$ subunit, providing a $30^{\circ}$ relative movement of the ring with respect to the $a$ subunit. In an alternative, a negative charge, or 'proton hole', is envisaged. This traverses the ring until it encounters an $\epsilon$ subunit, which is then displaced to an adjacent $c$ subunit, accomplishing a $30^{\circ}$ rotation of the $\epsilon-\gamma$ stalk.

Although progress, including the work of Rastogi and Girvin, is commendable, questions and uncertainties remain. In unveiling the details of how nature accomplishes this remarkable catalysis, we will probably uncover yet more surprising features.

Paul D. Boyer is at the Molecular Biology Institute, University of California, 611 Circle Drive East,

Los Angeles, California 90095-1570, USA.

e-mail:pdboyer@ucla.edu

1. Rastogi, V. K. \& Girvin, M. E. Nature 402, 263-268 (1999).

2. Mitchell, P. \& Moyle, J. Nature 213, 137-139 (1967).

3. Boyer, P. D. FEBS Lett. 58, 1-6 (1975).

4. Boyer, P. D. Аnпи. Rev. Biochem. 66, 717-749 (1997).

5. Abrahams, J. P., Leslie, A. G. W., Lutter, R. \& Walker, J. E Nature 370, 621-628 (1994).

6. Duncan, T. M., Bulygin, V. V., Hutcheon, M. L. \& Cross, R. L. Proc. Natl Acad. Sci. USA 92, 10964-10968 (1995).

7. Aggeler, R., Ogilvie, I. \& Capaldi, R. A. J. Biol. Chem. 272 , 19621-19624 (1997).

8. Sabbert, D., Engelbrecht, S. \& Junge, W. Nature 381, 623-628 (1996).

9. Noji, H. et al. Nature 386, 299-302 (1997).

10. Dmitriev, O. Y., Jones, P. C. \& Fillingame, R. H. Proc. Natl Acad. Sci. USA 96, 7785-7790 (1999).

erratum In the opening paragraph of the News and Views article "Carbon cycle: The blast in the past" (Nature 401, 752-755; 1999) the figure 2,000-4,000 gigatonnes of carbon should have been rendered as 2-4 million million tonnes or 2-4 billion billion grams (not 2-4 billion billion tonnes).
Daedalus

\section{Frankenstein lives!}

The adult immune system attacks foreign proteins ferociously, even those of a lifegiving transplant. Yet a fetus in the womb accepts foreign cells quite amicably. Even better, it thereafter regards them as part of itself. When adult, it will accept more transplants from the owner of the cells.

So Daedalus has a new strategy of organ transplantation. Take a cohort of expectant mothers, and extract some cells from each fetus by standard amniocentesis methods. Then inject each fetus with cells from all the others. They will grow up into a cohort of mutually immunocompatible adults, any of whom can give a transplant to any of the others, or receive one, with no rejection problems at all.

The organ-donor card of each member should specify his cohort; if he met a fatal accident, his organs could be given at once to any other members in need of them. Cohort members should be as closely related as possible, so that transplants between them would be physically as well as immunologically similar, and to give each member a sound genetic motive for providing another with a transplant. Mothers from one extended family, or from a fairly inbred village, are obvious cohort founders, but the bigger the cohorts the better. If (improbably) immunological tolerance is inherited, cohorts could be merged in successive generations until in time the whole of humanity shared the same immunological compatibility. But even a mass of small cohorts would revolutionize the transplant business. Rejection problems would cease, and recipients would no longer face a lifetime of drug-taking.

Transplant surgery would boom. Not only skin, hearts, livers and kidneys, but all parts of the body could be exchanged even brains and pieces of brain. The successful introduction of fetal brain tissue into adult brains suggests that a composite brain might rewire itself into a functional unit quite well. Total death could thus be averted. From a dozen oldsters, all suffering from different infirmities and brain deficits, a surgeon could assemble a perfectly healthy composite individual. The composite would have memories and skills from each of its predecessors, who would all survive as subsidiary personalities in the new joint venture.

David Jones

The Further Inventions of Daedalus (Oxford University Press), 148 past Daedalus columns expanded and illustrated, is now on sale. Special Nature offer: m.curtis@nature.com 


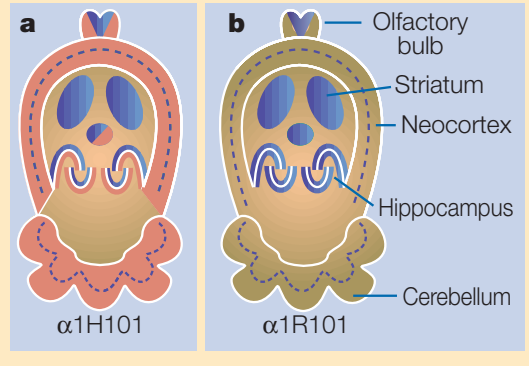

Figure 2 Distribution of benzodiazepine-binding sites in the mouse brain. a, In brain with a normal $\alpha 1$ gene $(\alpha 1 \mathrm{H} 101)$, the location of benzodiazepine-sensitive $\mathrm{GABA}_{\mathrm{A}}$ receptors with an $\alpha 1$ subunit is shown in pink, and $\mathrm{GABA}_{\mathrm{A}}$ receptors containing the $\alpha 2, \alpha 3$ and $\alpha 5$ subunits are in blue. Some parts of the brain (such as the hippocampus, cortex, olfactory bulb and thalamus) contain a mixture of receptor types, indicated by the overlap of blue and pink. Other brain areas, such as the striatum, contain mainly non- $\alpha 1$ receptors. $b$, In the $\alpha 1 \mathrm{R} 101$ mice made by Rudolph et al. ${ }^{1}$, the $\alpha 1$-containing receptors cannot bind benzodiazepines and only the $\alpha 2$, $\alpha 3$ and $\alpha 5$ sites remain. Large areas of the $\alpha 1 \mathrm{R} 101$ brain are insensitive - or, at least, less sensitive - to benzodiazepines.

$\alpha 1(\mathrm{H} 101 \mathrm{R})$ mice are healthy, ending speculation about the existence of natural benzodiazepine-like modulators. If histidine 101 were part of the binding site for these hypothetical molecules, this site would have vanished in the $\alpha 1(\mathrm{H} 101 \mathrm{R})$ mice, so they might, for example, have become more alert or slept less. But Rudolph et al. found no hints of such behaviour.

When the authors gave the mutant mice diazepam, however, there were two clear changes. First, the mice showed no sedation (measured by how much they run around and show an interest in their environment). And second, their memory was not impaired - at least, not for unpleasant events (going into a dark chamber and receiving an electric footshock). In contrast, when non-mutant mice were given the same dose of the drug they became sluggish, relaxed and apt to forget bad experiences.

These experiments highlight the importance of $\alpha 1$-containing $\mathrm{GABA}_{\mathrm{A}}$ receptors in the brain circuits that control general arousal and certain types of memory. However, the anxiety-reducing properties of benzodiazepines are just as potent in $\alpha 1$ (H101R) mice as in controls. In other words, the anxiety-reducing effects of benzodiazepines are distinct from their general sedative actions (until now, an open question), and must depend instead on $\mathrm{GABA}_{\mathrm{A}}$ receptors with $\alpha 2$, $\alpha 3$ or $\alpha 5$ subunits.

Maintenance of muscle tone also seems to be independent of $\alpha 1$-containing receptors, because the $\alpha 1(\mathrm{H} 101 \mathrm{R})$ mutants became clumsy when treated with diazepam. And the ability of benzodiazepine drugs to enhance the effects of alcohol - a fact reflected in road-death statistics - is also independent of the $\alpha 1$ subunit, as the $\alpha 1(\mathrm{H} 101 \mathrm{R})$ mice were affected just as strongly as wild-type animals by alcohol/benzodiazepine cocktails. Receptors containing the $\alpha 2$ and $\alpha 3$ subunits (which, unlike those containing $\alpha 1$, are expressed in the spinal cord) are likely candidates. But $\alpha 1$ subunits might still be involved in the other ill effects of combining alcohol and benzodiazepines, such as memoryblackouts.

Can drugs be developed that are specific for $\mathrm{GABA}_{\mathrm{A}}$-receptor subtypes, and hence for, say, anxiety-reducing effects? 'Proof-ofprinciple' successes with $\alpha 5$ - and $\alpha 6$-selective compounds ${ }^{9,10}$ indicate that such drugs are not far away. The technique described by Rudolph et al. is equally applicable to genes for the $\alpha 2, \alpha 3$ and $\alpha 5$ subunits (Fig. 2). The corresponding H101R mutants will narrow down which behaviours are influenced by which receptor type, and these results can be combined with large-scale screening for drugs on cloned receptors. The promise for the future is a directed search for drugs to treat conditions including anxiety, insomnia and epilepsy.

William Wisden is at the MRC Laboratory of

Molecular Biology, Hills Road, Cambridge

CB2 2QH, UK.

e-mail:ww1@mrc-lmb.cam.ac.uk

David N. Stephens is in the Department of

Experimental Psychology, University of Sussex,

Falmer, Brighton BN1 9QG, UK.

e-mail:dns@biols.susx.ac.uk

1. Rudolph, U. et al. Nature 401, 796-800 (1999).

2. Barnard, E. A. et al. Pharmacol. Rev. 50, 291-313 (1998).

3. Mckernan, R. M. \& Whiting, P. Trends Neurosci. 19, 139-143 (1996).

4. Sigel, E. \& Buhr, A. Trends Pharmacol. Sci. 18, 425-429 (1997)

5. Günther, U. et al. Proc. Natl Acad. Sci. USA 92, 7749-7753 (1995).

6. Homanics, G. E. et al. Proc. Natl Acad. Sci. USA 94, 4143-4148 (1997).

7. Wieland, H. A., Lüddens, H. \& Seeburg, P. H. J. Biol. Chem. 267, 1426-1429 (1992)

8. Kleingoor, C., Wieland, H. A., Korpi, E. R., Seeburg, P. H. \& Kettenmann, H. Neuroreport 4, 187-190 (1993).

9. Korpi, E. R. \& Lüddens, H. Br. J. Pharmacol. 120, 741-748 (1997).

10. Sur, C., Fresu, L., Howell, O., Mckernan, R. M. \& Atack, J. R. Brain Res. 822, 265-270 (1999).

Carbon cycle

\section{The blast in the past}

\section{Gerald R. Dickens}

0 n current estimates ${ }^{1-3}$, over a period of less than a thousand years 2,000-4,000 gigatonnes of carbon will be added to the atmosphere by human activity. That's $2-4$ billion billion tonnes. What will be the consequence of this rapid and massive release of carbon? The question has been tackled primarily with numerical simulations of the global carbon cycle constrained by experiments, present-day observations and records from the late Quaternary, the past 200,000 years or so of Earth history.

An alternative - studying ancient blasts of carbon - has always seemed pointless simply because we thought that there weren't any such blasts; as many of us know, natural processes cannot suddenly add enormous amounts of carbon to the ocean or atmosphere $^{2}$. That view of the global carbon cycle is spectacularly flawed, however, as highlighted in the paper by Norris and Röhl on page 775 of this issue ${ }^{4}$.

For just a brief period, about 55 million years ago, temperatures at high latitudes and in the deep oceans soared by $5-7{ }^{\circ} \mathrm{C}$ (refs 5-7). This event, called the late Palaeocene thermal maximum or $\mathrm{LPTM}^{6}$, coincided with an extraordinary decrease in the ${ }^{13} \mathrm{C} /{ }^{12} \mathrm{C}$ ratio $\left(\delta^{13} \mathrm{C}\right)$ of all carbon on the Earth's surface $e^{5,7-9}$. In sequences of marine sediments examined to date, this isotope anomaly is an abrupt drop in $\delta^{13} \mathrm{C}$ of -2.5 to $-3 \%$ over 5 to $20 \mathrm{~cm}$ followed by a roughly exponential return to near-initial values over 1 to $4 \mathrm{~m}$ (refs 5,7,9). The magnitude, shape and widespread nature of the isotope anomaly indicate a massive input of carbon to the ocean or atmosphere from an external reservoir greatly enriched in ${ }^{12} \mathrm{C}$, followed by a gradual return to earlier conditions ${ }^{7,9,10}$.

Time is central to understanding carbon input during the LPTM. Based on long-term sedimentation rates at several marine locations, previous studies ${ }^{5,7,9}$ suggested that the abrupt drop and gradual return in $\delta^{13} \mathrm{C}$ spanned less than 10,000 years and about 140,000 years, respectively. But such an interpretation necessarily implies that carbon was being added to the ocean or atmosphere at rates approaching or exceeding those of present-day anthropogenic inputs $^{7,10}$. Clearly, we have a dilemma: either models of the global carbon cycle are incomplete at a basic level, or the inferred timing of the $\delta^{13} \mathrm{C}$ anomaly is incorrect. Without a detailed timescale across the LPTM, one can certainly attribute the apparently rapid occurrence of the $\delta^{13} \mathrm{C}$ anomaly to a fanciful interpretation of the geological record.

During 1997, the Ocean Drilling Program recovered a continuous sediment sequence across the LPTM from a hole (site 1051) in the western Atlantic Ocean ${ }^{4,11}$. Unlike all previously recovered late Palaeocene sections, this record contains obvious cycles in sediment composition. 
What Norris and Röhl ${ }^{4}$ have done is to quantify the amplitude and thickness of each cycle over a considerable length of the upper Palaeocene and lower Eocene, between 54 and 56 million years ago. Then, following numerous previous studies of marine sediment, they show that the observed sediment cycles have a regular frequency consistent with the Earth's precessional period of about 20,000 years. Using this astronomically calibrated timescale for the Palaeocene-Eocene transition, they conclude that the abrupt decrease and gradual return in $\delta^{13} \mathrm{C}$ at site 1051 indeed took less than 10,000 years and about 140,000 years, respectively (Fig. 1). The full $2.5-3 \%$ amplitude of the isotope anomaly is not evident in the bulk carbonate record, probably because the bulk record includes variable amounts of carbon from deep- and shallow-ocean reservoirs. Nevertheless, the data concerned look solid: there is now no question that the isotope composi-

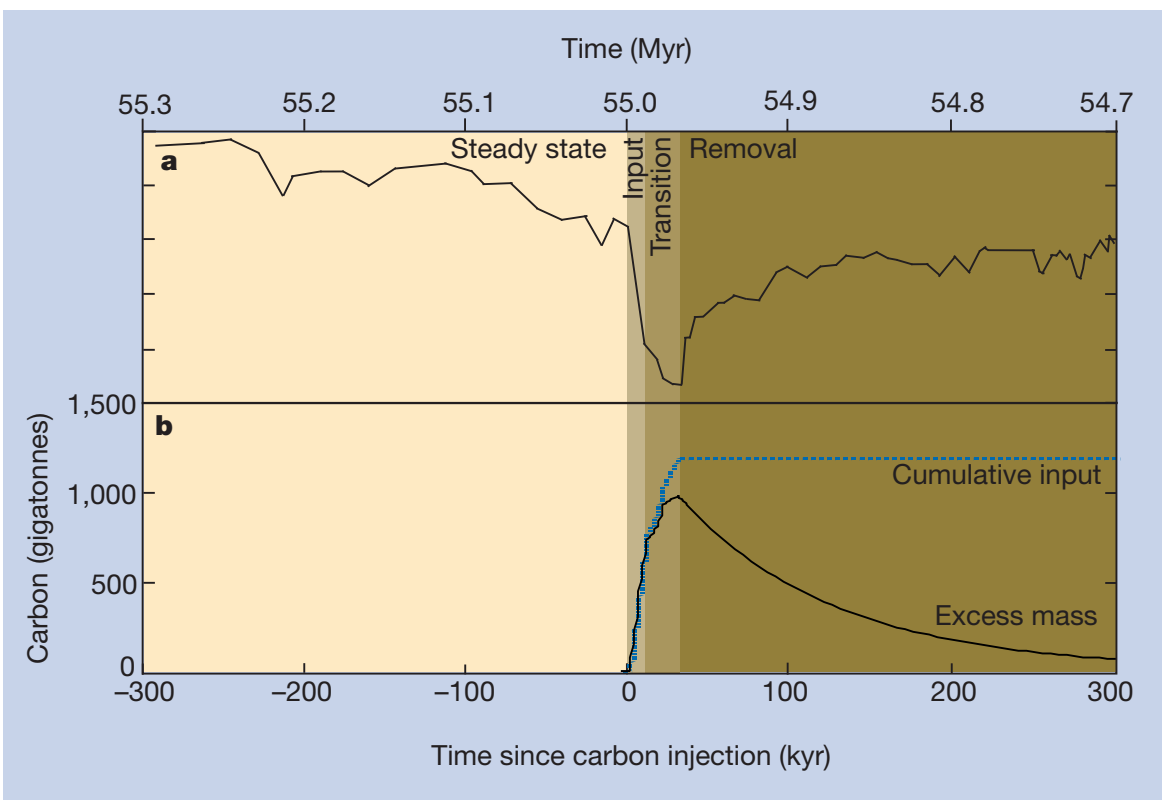

Figure 1 States of carbon around the late Palaeocene thermal maximum (LPTM), 55 million years ago. a, Norris and Röhl's astronomically calibrated carbon isotope $\left(\delta^{13} \mathrm{C}\right)$ record across the LPTM at Ocean Drilling Program site 1051. b, Step-wise integration of the time-record according to massbalance equations ${ }^{10,13}$ to obtain a methane carbon-source function. This simple analysis of the $\delta^{13} \mathrm{C}$ record gives a minimum carbon input during the LPTM in gigatonnes. It assumes present-day values for the global carbon cycle ${ }^{2,10}$ and does not consider additional carbon input from dissolution of carbonate.

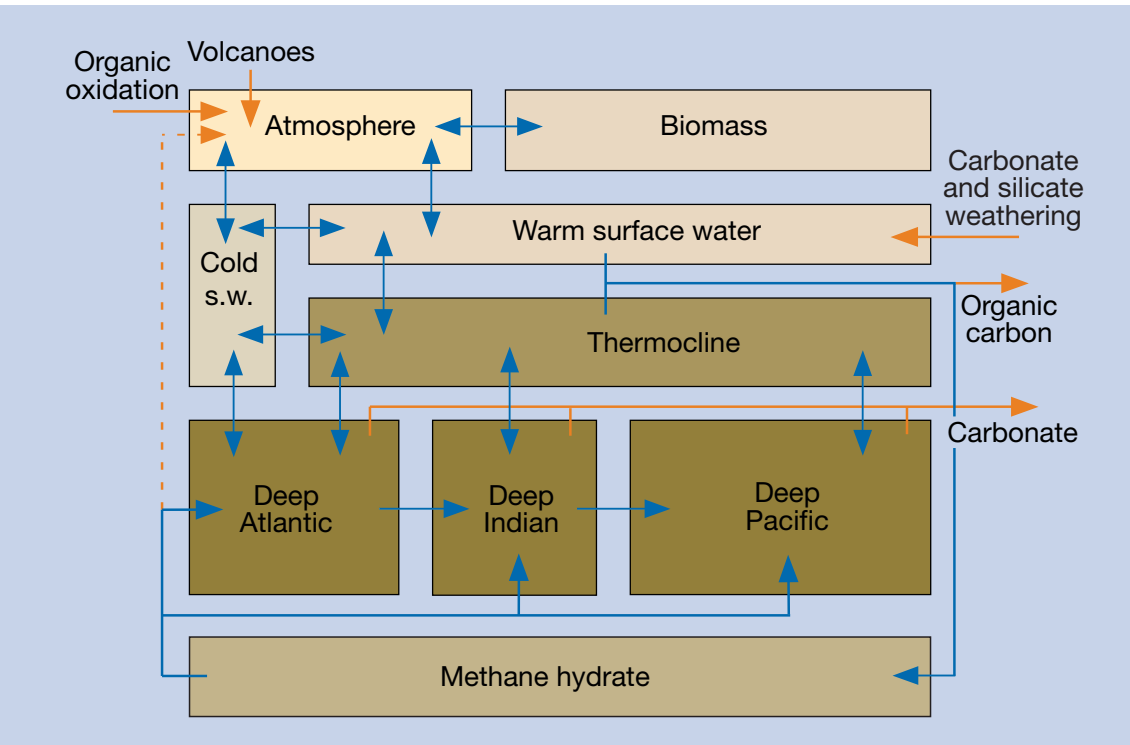

Figure 2 Model of the exogenic carbon cycle that includes a large gas-hydrate capacitor. The major carbon reservoirs, including gas hydrates, are connected by internal exchange fluxes (blue arrows). Carbon is added to and removed from these reservoirs by external exchange fluxes with the rock cycle (orange arrows). The sizes (masses) of reservoirs are not drawn to scale.

tion of all major carbon reservoirs suddenly changed during the LPTM.

These new records across the LPTM force us to reconstruct the widely held models of the global carbon cycle. Specifically, there must be a large reservoir that, in the distant past, has sporadically been able to add huge quantities of ${ }^{12} \mathrm{C}$-rich carbon to the ocean or atmosphere over very short periods of time. As discussed by Norris and Röhl ${ }^{4}$, and others $^{9-11}$, the best explanation is that the carbon cycle contains a large gas-hydrate capacitor (Fig. 2) because no other reservoir contains a large mass of carbon sufficiently enriched in ${ }^{12} \mathrm{C}$. Gas hydrates are ice-like solids composed of gas and water that are stable at high pressure, low temperature and high gas concentration ${ }^{12}$. We know that sediment on continental slopes contains enormous quantities of ${ }^{12} \mathrm{C}$-rich carbon as $\mathrm{CH}_{4}$ (methane) hydrate ${ }^{12}$, and that has presumably been the case throughout time. Carbon input fluxes to this global gas-hydrate capacitor (conversion of organic matter to $\mathrm{CH}_{4}$ ) have probably been similar to carbon output fluxes (oxidation of $\mathrm{CH}_{4}$ to $\Sigma \mathrm{CO}_{2}$ ) over most of the geological record. But during the $5-7-{ }^{\circ} \mathrm{C}$ deep-ocean warming at the LPTM, the cause of which remains unclear, it seems that thermal dissociation of gas hydrate caused $\mathrm{CH}_{4}$ release rates greatly to exceed production rates ${ }^{10}$. The result was a massive and rapid input of at least 1,000 gigatonnes of ${ }^{12} \mathrm{C}$-rich carbon into the ocean and atmosphere (Figs 1,2).

Carbon we add to the atmosphere today will eventually precipitate as carbonate and organic carbon ${ }^{2,3}$. In the debate over the parameters and feedbacks that govern such carbon sequestering, present-day observations and Quaternary records offer only limited help. In theory, future removal of anthropogenic input of carbon into the environment could be tracked by a quasi-exponential increase in the $\delta^{13} \mathrm{C}$ of the ocean or atmosphere ${ }^{3,13}$. If the carbon cycle 55 million years ago operated in a similar way to the way it does now, the record presented by Norris and Röhl ${ }^{4}$ implies that the carbon we inject over the coming millennium will remain with us in the ocean, atmosphere and biomass for at least another 120,000 years.

During the LPTM, the first 10,000 years after massive carbon input when $\delta^{13} \mathrm{C}$ is relatively constant are particularly important, because this indicates a transition period when inputs and outputs of the global carbon cycle are balanced. Norris and Röhl ${ }^{4}$ and Bains et al. ${ }^{11}$ suggest that this was a time of diminished $\mathrm{CH}_{4}$ input (Fig. 2). A global carbon cycle that cannot remove carbon immediately after massive carbon injection is a provocative alternative. With a revised model for the global carbon cycle, and a single, well-dated late Palaeocene section, we can now begin to view aspects of Earth's future in an entirely new light. 


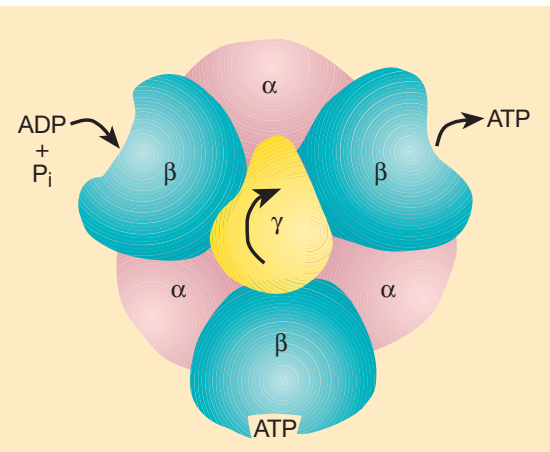

Figure 2 How rotation of the $\gamma$ subunit drives catalysis. During ATP synthesis, rotation of the $\gamma$ subunit causes sequential changes in the $\beta$ subunits. A rotation of $120^{\circ}$ changes the $\beta$ subunit that binds ADP and $P_{i}$ to a form with tightly bound ATP. The subunit with tightly bound ATP then changes to a form that releases ATP, and the third subunit prepares to bind another ADP and $P_{i}$.

ability of the X-ray structure also allowed clever disulphide cross-linking experiments to be designed, showing the positional interchange of the $\beta$ subunits as catalysis proceeds $s^{6,7}$. Specialized fluorescence techniques provided strong evidence for the rotation ${ }^{8}$. Rotational catalysis finally became widely accepted in 1997 when Noji et al. ${ }^{9}$ dramatically showed the rotation directly. They attached a fluorescently labelled actin filament to the $\gamma$ subunit of the $F_{1}$ portion fixed on a slide, then watched the filament spin as the enzyme cleaved ATP.

Other studies have looked into the arrangement of the subunits (Fig. 1). The many copies of the $c$ subunit in the $\mathrm{F}_{0}$ portion are arranged in a ring, with a conserved carboxyl group near the middle of one of the two hydrophobic helices that cross the membrane. These two helices are connected by a polar loop with conserved residues. The $b$ and $\delta$ subunits form a stator, which assures that rotational movement of the $\gamma$ subunit drives conformational changes in the $\beta$ subunits. The $\epsilon$ and $\gamma$ subunits contact each other and the polar loop of subunit $c$. The $a$ subunit contacts the ring of $c$ subunits and provides groups that probably participate in proton transfer through the $\mathrm{F}_{0}$ portion. Such proton transfer is thought to cause the ring of $c$ subunits to move in a step-wise fashion relative to the $a$ subunit. This results, in turn, in rotation of the $\epsilon$ and $\gamma$ subunits.

But does proton translocation cause meaningful changes in the conformation of the $c$ subunit - changes that might drive the rotation? This is the problem that has been elegantly addressed by Rastogi and Girvin ${ }^{1}$. To do this, they used two main methods. One was to measure the location and distance constraints provided by selected cysteine insertions that allowed disulphide-bond formation. The other was NMR, which gave structure and distance constraints from ${ }^{13} \mathrm{C}$ - and ${ }^{15} \mathrm{~N}$-resolved three-dimensional NOESY data.

Fillingame and colleagues ${ }^{10}$ have used the NMR approach to provide a structure for the monomeric $c$ subunit. Combining this with disulphide-crosslinking and other data, these authors developed a model for the structure of the $c$-subunit ring and its interactions with the $a$ subunit. They found that the key residue, an aspartic acid at position 61 (Asp 61), was lodged at the centre of four $\alpha$-helices of a $c-c$ dimer. They proposed that, as deprotonation and protonation occur when the ring of $c$ subunits interacts with the a subunit, the critical carboxyl group might move towards the periphery of the ring by a swivelling of adjacent helices.

The oligomeric model developed by Rastogi and Girvin ${ }^{1}$ provides insight into the catalytic mechanism. These authors deduced the conformations of the protonated and deprotonated forms of the $c$ subunit. When Asp 61 is deprotonated, there is a dramatic $140^{\circ}$-rotation of the carboxy-terminal helix with respect to the amino-terminal helix. The authors suggest two ways in which rotation of this helix might drive rotation of the $\gamma$ subunit. In one, the $a$ subunit moves with the carboxy-terminal helix of the $c$ subunit, providing a $30^{\circ}$ relative movement of the ring with respect to the $a$ subunit. In an alternative, a negative charge, or 'proton hole', is envisaged. This traverses the ring until it encounters an $\epsilon$ subunit, which is then displaced to an adjacent $c$ subunit, accomplishing a $30^{\circ}$ rotation of the $\epsilon-\gamma$ stalk.

Although progress, including the work of Rastogi and Girvin, is commendable, questions and uncertainties remain. In unveiling the details of how nature accomplishes this remarkable catalysis, we will probably uncover yet more surprising features.

Paul D. Boyer is at the Molecular Biology Institute, University of California, 611 Circle Drive East,

Los Angeles, California 90095-1570, USA.

e-mail:pdboyer@ucla.edu

1. Rastogi, V. K. \& Girvin, M. E. Nature 402, 263-268 (1999).

2. Mitchell, P. \& Moyle, J. Nature 213, 137-139 (1967).

3. Boyer, P. D. FEBS Lett. 58, 1-6 (1975).

4. Boyer, P. D. Аnпи. Rev. Biochem. 66, 717-749 (1997).

5. Abrahams, J. P., Leslie, A. G. W., Lutter, R. \& Walker, J. E Nature 370, 621-628 (1994).

6. Duncan, T. M., Bulygin, V. V., Hutcheon, M. L. \& Cross, R. L. Proc. Natl Acad. Sci. USA 92, 10964-10968 (1995).

7. Aggeler, R., Ogilvie, I. \& Capaldi, R. A. J. Biol. Chem. 272 , 19621-19624 (1997).

8. Sabbert, D., Engelbrecht, S. \& Junge, W. Nature 381, 623-628 (1996).

9. Noji, H. et al. Nature 386, 299-302 (1997).

10. Dmitriev, O. Y., Jones, P. C. \& Fillingame, R. H. Proc. Natl Acad. Sci. USA 96, 7785-7790 (1999).

erratum In the opening paragraph of the News and Views article "Carbon cycle: The blast in the past" (Nature 401, 752-755; 1999) the figure 2,000-4,000 gigatonnes of carbon should have been rendered as 2-4 million million tonnes or 2-4 billion billion grams (not 2-4 billion billion tonnes).
Daedalus

\section{Frankenstein lives!}

The adult immune system attacks foreign proteins ferociously, even those of a lifegiving transplant. Yet a fetus in the womb accepts foreign cells quite amicably. Even better, it thereafter regards them as part of itself. When adult, it will accept more transplants from the owner of the cells.

So Daedalus has a new strategy of organ transplantation. Take a cohort of expectant mothers, and extract some cells from each fetus by standard amniocentesis methods. Then inject each fetus with cells from all the others. They will grow up into a cohort of mutually immunocompatible adults, any of whom can give a transplant to any of the others, or receive one, with no rejection problems at all.

The organ-donor card of each member should specify his cohort; if he met a fatal accident, his organs could be given at once to any other members in need of them. Cohort members should be as closely related as possible, so that transplants between them would be physically as well as immunologically similar, and to give each member a sound genetic motive for providing another with a transplant. Mothers from one extended family, or from a fairly inbred village, are obvious cohort founders, but the bigger the cohorts the better. If (improbably) immunological tolerance is inherited, cohorts could be merged in successive generations until in time the whole of humanity shared the same immunological compatibility. But even a mass of small cohorts would revolutionize the transplant business. Rejection problems would cease, and recipients would no longer face a lifetime of drug-taking.

Transplant surgery would boom. Not only skin, hearts, livers and kidneys, but all parts of the body could be exchanged even brains and pieces of brain. The successful introduction of fetal brain tissue into adult brains suggests that a composite brain might rewire itself into a functional unit quite well. Total death could thus be averted. From a dozen oldsters, all suffering from different infirmities and brain deficits, a surgeon could assemble a perfectly healthy composite individual. The composite would have memories and skills from each of its predecessors, who would all survive as subsidiary personalities in the new joint venture.

David Jones

The Further Inventions of Daedalus (Oxford University Press), 148 past Daedalus columns expanded and illustrated, is now on sale. Special Nature offer: m.curtis@nature.com 
Gerald R. Dickens is in the School of Earth Sciences, James Cook University, Townsville, Queensland 4811, Australia.

e-mail: Jerry.Dickens@jcu.edu.au

1. Carbon Dioxide Information Analysis Center (CDIAC) http://cdiac.esd.ornl.gov/trends/trends.htm

2. Sundquist, E. T. in The Changing Carbon Cycle: A Global Analysis (eds Trabalka, J. R. \& Reichle, D. E.) 371-402

(Springer, New York, 1986).

3. Walker, J. C. G. \& Kasting, J. F. Palaeogeogr. Palaeoclimatol.

Palaeoecol. 97, 151-189 (1992).

4. Norris, R. D. \& Röhl, U. Nature 401, 775-778 (1999).

Kennett, J. P. \& Stott, L. D. Nature 353, 225-229 (1991).
6. Zachos, J. C., Lohmann, K. C., Walker, J. C. G. \& Wise, S. W. J. Geol. 101, 191-213 (1993).

7. Thomas, E. \& Shackleton, N. J. Correlations of the Early Paleogene in Northwest Europe Geol. Soc. Spec. Publ. 101 (eds Knox, R. O. et al.) 401-411 (Geological Society, London, 1996).

8. Koch, P. L., Zachos, J. C. \& Gingerich, P. D. Nature 358, 319-322 (1992).

9. Bralower, T. J. et al. Geology 25, 963-966 (1997).

10. Dickens, G. R., O’Neil, J. R., Rea, D. K. \& Owen, R. M. Paleoceanography 10, 965-971 (1995).

11. Bains, S., Corfield, R. M. \& Norris, R. D. Science 285, 724-727 (1999).

12. Kvenvolden, K. A. Rev. Geophys. 31, 173-187 (1993).

13. Berger, W. H. \& Vincent, E. Geol. Rundsch. 75, 249-269 (1986).

Immunology

\section{Toll gates for pathogen selection}

Richard J. Ulevitch

A 11 species need an immediate, systemic reply to the microbial pathogens in their environment. This reply known as the innate immune response - is characterized by the de novo production of mediators that either kill the pathogen directly or induce phagocytic cells to ingest and kill it. In the fruit fly Drosophila melanogaster, distinct cell-surface receptors belonging to the Toll family mediate separate anti-bacterial and anti-fungal responses in the same type of cell ${ }^{1}$. They do this by inducing genes that encode anti-microbial peptides.

Does this model describe the situation in mammalian systems? On page 811 of this issue, Underhill et al. ${ }^{2}$ describe the ligand specificity of two members of the mammalian Toll-like receptor family, TLR2 and TLR4. These data show that the situation is indeed similar to that in Drosophila - that is, two distinct Toll-like receptors, both expressed in macrophages, discriminate between different microbial pathogens or their products. Whereas TLR4 is the main protein involved in recognizing Gram-negative bacteria and lipopolysaccharide (a glycolipid constituent of the bacterial outer membrane), TLR2 is the key in responses to other types of microbial pathogen, such as yeast and Gram-positive bacteria.

The innate immune response is often driven through recognition, by the host cell, of surface components of the microbial pathogen. Monocytes and macrophages are central to the intensity and specificity of this response. Most - if not all - microbial pathogens are thought to activate the innate immune system using mechanisms with common features. For example, many macrophages contain a surface protein called CD14, which binds ligands such as lipopolysaccharide and triggers an innate immune response ${ }^{3}$. But CD14 is not thought to participate directly in signalling. Rather, one or more of the mammalian Toll-like receptors acts in concert with CD14 to discriminate between microbial pathogens or their products ${ }^{1}$ and initiate transmembrane signalling.

Mammalian cells may express as many as ten distinct Toll-like receptors ${ }^{4}$. All span the cell membrane, with repeating leucine-rich repeats in the external domain and a common sequence motif - the Toll-homology domain - in the cytoplasmic tail. Members of the interleukin-1 receptor family, which is another essential element of the innate immune system, also contain a Toll-homology domain in their cytoplasmic tails. Most attention has been paid to the TLR2 and TLR4 proteins, and the importance of TLR4 in responses to Gram-negative bacteria and lipopolysaccharide was first suggested by powerful genetic data. Beutler and colleagues ${ }^{5}$ established that TLR4 is encoded by the lipopolysaccharide (Lps) gene, and that it controls sensitivity to this molecule. Akira and colleagues ${ }^{6}$ also showed that mice in which the TLR4 gene has been deleted have the same defects as mice with mutations in Lps.

But some reports indicate that lipopolysaccharide acts via TLR2. When TLR2 is expressed in cell lines that do not normally produce it, these cells become able to respond to lipopolysaccharide. Moreover, in at least one case, lipopolysaccharideinduced activation of a monocytic cell line is

\section{Earth science \\ Mercurial vents}

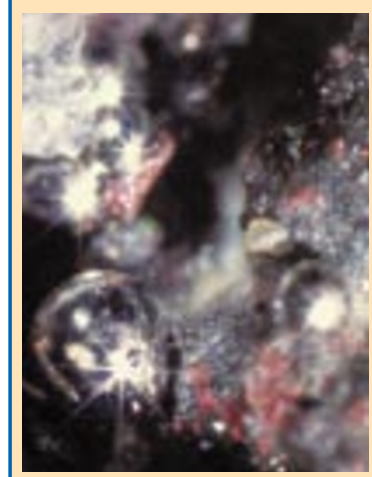

On the land, many hot springs are enriched in trace metals, and have laid down economically important deposits of gold, silver and mercury. Now, Peter Stoffers from Kiel University and coworkers from Canada and New Zealand have discovered the first mercury-producing hot springs under the sea, in water $200 \mathrm{~m}$ deep off the coast of New Zealand's North Island (Geology 27, 931-934; 1999).

The mercurydepositing vents are part of more than 20 in two groups discovered in the Whakatane graben, a fault-bounded depression on the sea floor. They are inhospitable, if colourful, places, reaching temperatures of $200^{\circ} \mathrm{C}$, laying down thick crusts of arsenic and sulphur, and producing liquid hydrocarbons from the 'cracking' of organic matter - many of the samples came up coated in an oily film that smelt of petroleum. The vents are inhabited by mats of bacteria that can metabolize sulphur.

The vents are also almost saturated with mercury. Much of it is present as cinnabar $(\mathrm{HgS}$; the red crusts in the picture), but Stoffers et al. estimate that about $10 \%$ exists as free mercury, some of which may have condensed from a mercury vapour formed inside the boiling vents. The water pressure forces some of the mercury into pores in the rocks, silver droplets of which are released when the samples are brought to the surface .

The origin of the mercury is uncertain. The basement rocks beneath the vents are shales and graywackes (a form of sandstone). These rock types have been found to contain large mercury deposits which formed in the past and, as this result shows, formation may still be going on. Shales are rich in hydrocarbons, which would explain their presence in the vents. Mercury could also be entering the vents from nearby volcanoes. Stoffers et al. speculate that hydrothermal vents around the world could be adding sizeable amounts of mercury to the sea. That in some places this mercury could end up in fish and eventually humans is an obvious, although unquantified, concern. John Whitfield 